\title{
The learningscape of a virtual design atelier
}

\section{Jennefer Hart, Theo Zamenopoulos, Steve Garner The Open University}

\section{Abstract}

The development of e-learning platforms is fundamentally changing the nature of education across all disciplines. Art and design education has traditionally taken place within a studio environment and its model of teaching and learning has been informed by the 'atelier' approach which has a distinctive educational and cultural history. Significant pressures arise today in undergraduate art and design education and partly these drive the need to establish an effective and viable modern studio experience. Not only must any new studio support student learning of practice and principles, for example, by allowing students to work alongside experts, it must foster the community and culture of the creative industries. As if this wasn't difficult enough, any innovation in teaching and learning must not incur the huge costs and resource demands of our current models of art and design education and it must be scalable to provide a stimulating experience for large numbers of students with diverse backgrounds, abilities and needs. This paper reports on a suite of studies that were carried out as part of a JISCfunded project titled ATELIER-D. The aim of the project was to create an online virtual design learning environment that replicates and improves the features of traditional face-to-face studio education. The paper makes reference to new curricula at the Open University, particularly a new FHEQ level 4 online design course fi rst presented in February 2010 to 350 students.

\section{Tradition and opportunity}

One of the traditional drawbacks to distance education is that student learning has largely taken place in isolation. The peer community is widely distributed and, save a few day-school experiences, students have lacked the opportunity to interact with each other. Tutors have been limited to one-to-one exchanges. But new technologies have given rise to new opportunities. Through ICT it has, for example, become possible to offer students and tutors shared virtual spaces that go some way towards simulating the shared spaces found in traditional face-to-face undergraduate education. This is particularly significant for art and design 
education. The opportunity for distance learning institutions, such as the Open University, concerns the ability to create an effective model of online design education. But there is a second and much broader possibility for those universities providing a more traditional face-to-face education service. There exists a major opportunity to create an effective hybrid model that combines appropriate face-to-face interaction whilst taking advantage of new tools for online collaborative learning.Not only would the new model be more sustainable, but the work reported here suggests there are opportunities for qualitative improvements in art and design learning.

The teaching of art and design at university level is an activity-based process that taps into the expertise of skilled practitioners. Studio design teaching, using problem-based learning (PBL), predominates. This model, widely documented by Kvan, 2001, Broadfoot \& Bennett, 2003, etc., involves students addressing ill-defi ned problems and communicating and justifying their outputs under the guidance of expert practitioners. Over the past two decades the professional creative process has become more collaborative involving various specialists working together. More recently, advancements in Web 2.0 technologies have provided opportunities for those engaged in professional practice and education to communicate and share their ideas online. The adoption of new technologies for creative collaboration has changed the landscape of the design professions and thus the learningscape of design education. The merging of traditional design skills and new digital working practices within new social networking structures is giving rise to a new design pedagogy and impacting on the teacher and student dynamic (Shao et al. 2007). It is within this context that the ATELIER-D project was devised and conducted.

\section{The ATELIER-D project}

This paper focuses on fi ndings and observations that have emerged from a two-year JISC-funded project titled 'Achieving Transformation, Enhanced Learning and Innovation through Educational Resources in Design' (ATELIER-D). The project is one of fi fteen addressing the theme 'transforming curriculum delivery through technology'. ATELIER-D sought to explore and develop new models of fl exible distance learning by drawing on the design studio model of teaching and learning. There have been earlier online design studios, for example the Omnium project from the University of New South Wales (UNSW) Australia (Bennett \& Dziekan, 2005), and the ICON project from Strathclyde University (Sclater, et al. 2001). Some of these have been domain-specifi c such as those aimed at supporting architectural practice (Broadfoot and Bennett, 2003). ATELIER-D sought to go beyond the creation of a studio to explore, as its title suggests, innovation and enhanced learning. Here there are many fewer published studies.

This paper is presented in four parts. First, it outlines the context of the study, identifying some of the core features of a virtual environment for design teaching and learning. Second, it discusses some of the 
technologies studied in the project in relation to three core requirements: (a) the creation of a social environment for teaching and learning, (b) the facilitation of reflective practice through collaboration, and (c) the development of a platform for communication and learning across different courses. The third part reports on some key findings and observations and the final part reflects on issues emerging from the project.

\section{Design learning and the legacy of the atelier}

As noted above, the origin of design studio-based learning lies in the art atelier model and dates back at least three centuries. In this, young apprentices worked alongside a master craftsperson or artist (Broadfoot \& Bennett ,2003). The model is founded on the principle of 'learning-by-doing' where students master a variety of technical skills and gain aesthetic training while working on tasks within a community. It is a type of learning that has much interested scholars in recent years (e.g. Schön, 1983). This traditional studiobased learning model proved effective in centres around the world up to the 1990s when new pressures emerged. Art and design found itself having to justify space for displays, meeting spaces, studios and workshops. In comparison to other subjects, staff-student ratios were viewed by senior management as generous. Costs of resources such as academic staff, technical staff, capital equipment and materials compounded the problem. There have been many moves towards rationalisation and efficiency, for example class sizes have increased, contact time between students and staff has decreased and new technologies such as virtual learning environments have been rolled out, but there have been no significant attempts to combine the best of the old model with the potential of the new. There has been little progress in combining the proven capacity of the atelier model with the broad range of computer-based tools available today.

Each year universities teach a myriad of design courses to classes of students who typically work in a shared environment. These design students work alongside their peers in a space where they interact, display work-in-progress and engage in private or parallel pursuits of common design tasks. Students work under the supervision of a design tutor who is, even today, likely to be a practitioner as well as an academic. Design projects present design problems that enable students to refine their knowledge through the reflective act of designing. Skills and knowledge are developed and demonstrated through students' design work. The design process is iterative, involving regular individual or group critiques where all participants provide feedback on each student's work. These critiques, or 'crits', are a distinctive component of studio-based learning. They facilitate the discreet transfer of tacit knowledge where design strategies, values and behaviours are played out through verbal and graphic communication, often supplemented with 3D constructions (Kvan, 2001). The use of peer-to-peer assessment can be very effective in stimulating progression and placing learning outcomes in practical contexts. The studio setting, 
which is both a work and a social environment, is seen as vital to facilitating the type of camaraderie required for creative learning.

\section{ATELIER-D technologies}

Within the ATELIER-D project a number of Web 2.0 technologies were evaluated in order to explore their potential in supporting a virtual design atelier. These studies took place across three design courses offered at the Open University which form the backbone of the bachelor degree in Design and Innovation. At the beginning of each course (in February 2009 and 2010), the course team invited students and tutors to participate in a number of studies. The participation in each study ranged from 8 to approximately 350 people. The age and educational background of students varied considerably as is the case with most Open University courses. Adopting an action research methodology, data were gathered and analysed using a mixed method approach. Qualitative data were gained from observations, questionnaires and interviews, and quantitative data were gained from technology data logs and analysed using statistical and social networking analysis (SNA) methods.

The ATELIER-D project took place over two years and is currently in its fi nal stages of evaluation. In the first year six small studies were conducted using a mix of Web 2.0 technologies. These included two social websites (Facebook and Flickr), a video conferencing tool (Elluminate), a knowledge mapping tool (Compendium), immersion in a virtual world (Second Life) and a bespoke studio tool developed at The Open University (OpenDesignStudio). Findings from these six studies informed the creation of three larger studies that took place within year two. The project process is illustrated in Figure 1.

In year two, technologies were selected to support both students and tutors across the design programme in order to explore three core aspects of the virtual design studio: (1) the formation of a social environment for learning and teaching (Ning), (2) the facilitation of refl ective process through designing and sharing experiences (OpenDesignStudio), and (3) the formation of a platform for communication between tutors across the degree programme (Google Wave). Discussion now turns to these three core studies. 


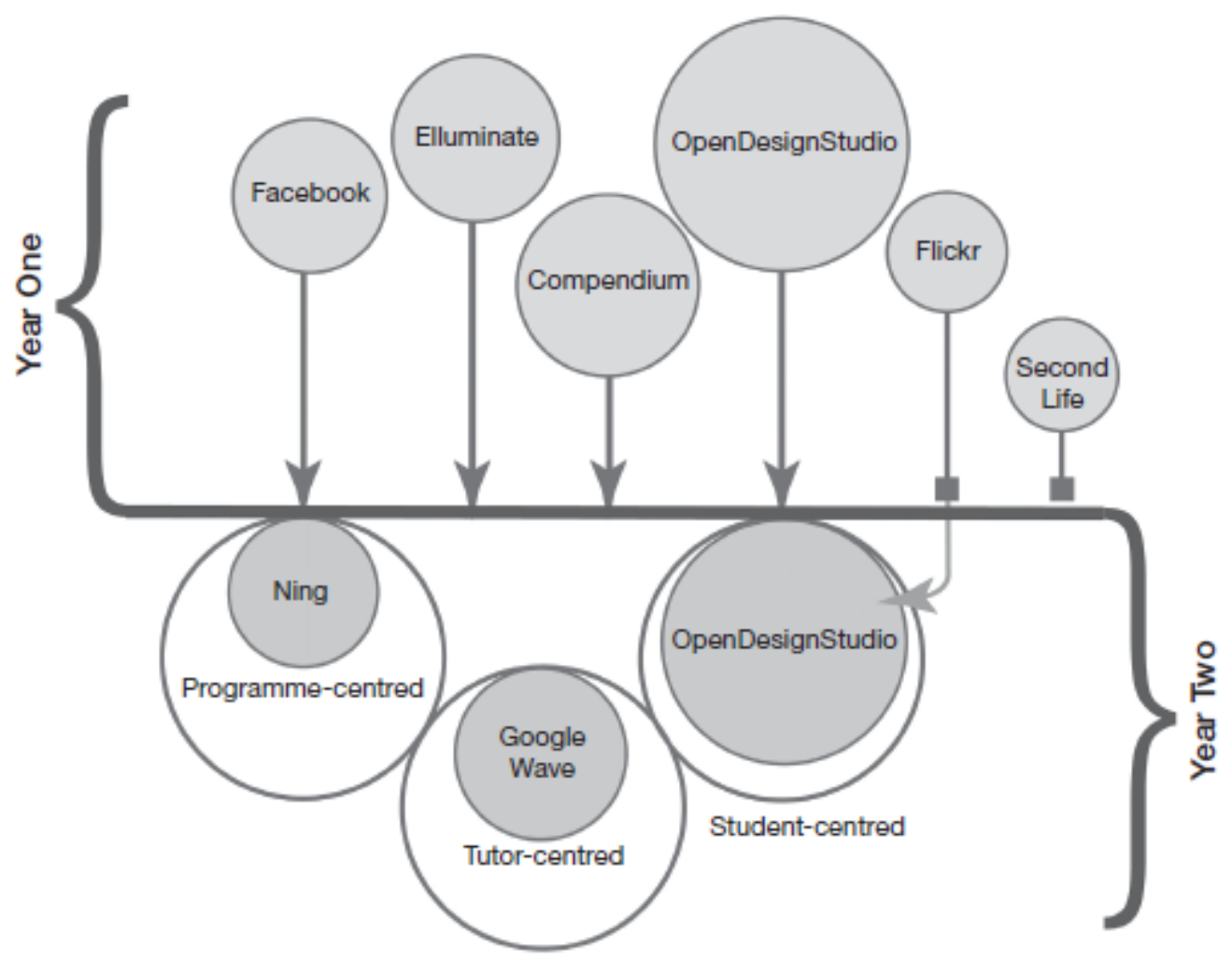

Figure 1 The ATELIER-D project process

\section{Creating a social environment for teaching and learning}

In year one a small Facebook study took place which provided clear indication that the use of social networking tools can have a positive impact in the building of a social community of designers. Creating a space for both students and tutors to participate across the design programme provides huge opportunities for informal learning. It facilitates the transfer of tacit knowledge, not just for design learning, but also for information and resources about the wider design profession. Social networking sites offer tools that allow students to personalise their own space and provide a shared virtual space where they can socialise, share resources, comment and discuss with each other.

A larger study took place in the second year involving volunteer students and tutors across the three Open University design courses. A Ning website was created (www.oudesig.ning.com), to provide a programmecentred network and facilitate communication across levels of study. The move from Facebook to the Ning platform was chosen for a number of reasons. Ning allowed both asynchronous and synchronous communication to take place thus providing an active space for live chat. Similar to Facebook, it promotes the sharing of pictures and video and allows users to create their own groups. But the ability to customize 
the website enabled the creation of a more personalised private space dedicated to the design community within the Open University. A screenshot is shown in Figure 2. The desigNing website was created in February 2010 and now has over 150 members across all three course programmes. The site provides three main functions. First it acts as a living repository of design resources based around videos, pictures and web-links uploaded by its members. Second, the uploaded artefacts (pictures, videos, links etc) provide the basis for communication within the network and third, the site provides a space for both synchronous and asynchronous events to take place, for example collaborative games, competitions and live events.

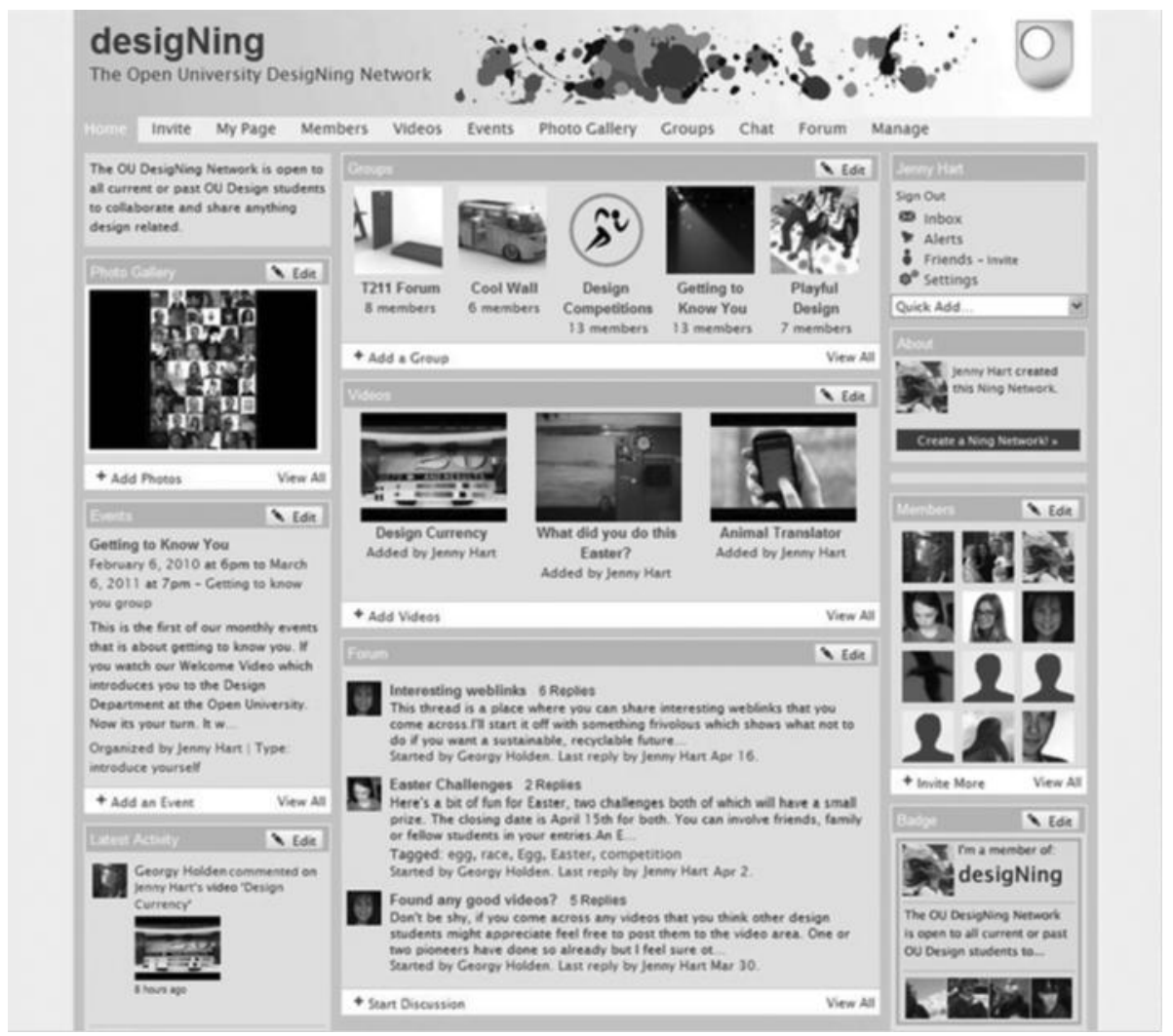

Figure 2 The Open University desigNing network

\section{Facilitating reflective practice through collaboration}

Traditional face-to-face design education allows for both formal and informal exchanges of design ideas through design artefacts (sketches, photos, models and prototypes). Sharing design ideas and engaging in reflective interaction is seen as a crucial part of the design process (Schön, 1983). These can take place in 
both formal and informal interactions. Formal exchanges typically take place during design critiques or reviews between students and tutors. Informal exchanges take place throughout the academic year and include student-to-student and student-to-tutor conversations, but also communication through pin-board or notice board displays.

As outlined above, in year one of the ATELIER-D project a number of technologies were explored with regards to their potential to facilitate reflective practice through collaboration between small numbers of students. Flickr was used for organizing design critiques, Elluminate for tutor-student communication, and Second Life for supporting collaboration in small projects. For year two, we assessed the technologies according to three criteria: a) the scalability of these platforms for use by a very large number of students, b) the effort required by students and tutors in order to familiarise themselves with the new technologies and be able to effectively use them, and c) the possibility of customising the technologies so that they are tightly integrated with the main structure and learning objectives of the individual courses. Second Life requires significant training before students and tutors are able to use it effectively in design and it is difficult to implement for large cohorts. Flickr was found to be quite complex to use and it lacked customization tools. Elluminate was found to be very beneficial as a tool for organising synchronous meetings, tutorials and online workshops, yet took time for its users to overcome the technical issues and become confident users. However, Elluminate offers potential to be used with other technologies, but was not considered core as it lacks the ability to sustain an off-line collaborative space.

Given these drawbacks the team decided to continue with the bespoke e-portfolio tool OpenDesignStudio developed by The Open University's Learning and Teaching Solutions unit. This was created in parallel with the new FHEQ level 4 course: U101 'Design Thinking: Creativity for the 21st Century', first presented in February 2010. OpenDesignStudio is an image-sharing interface that allows students to share photos, scans and information with their peers and tutors as well as submit work for formal assessment. Students are encouraged to upload their ideas, comment on the work of others, and share their learning experience with the community of designers (tutors) and design learners. 


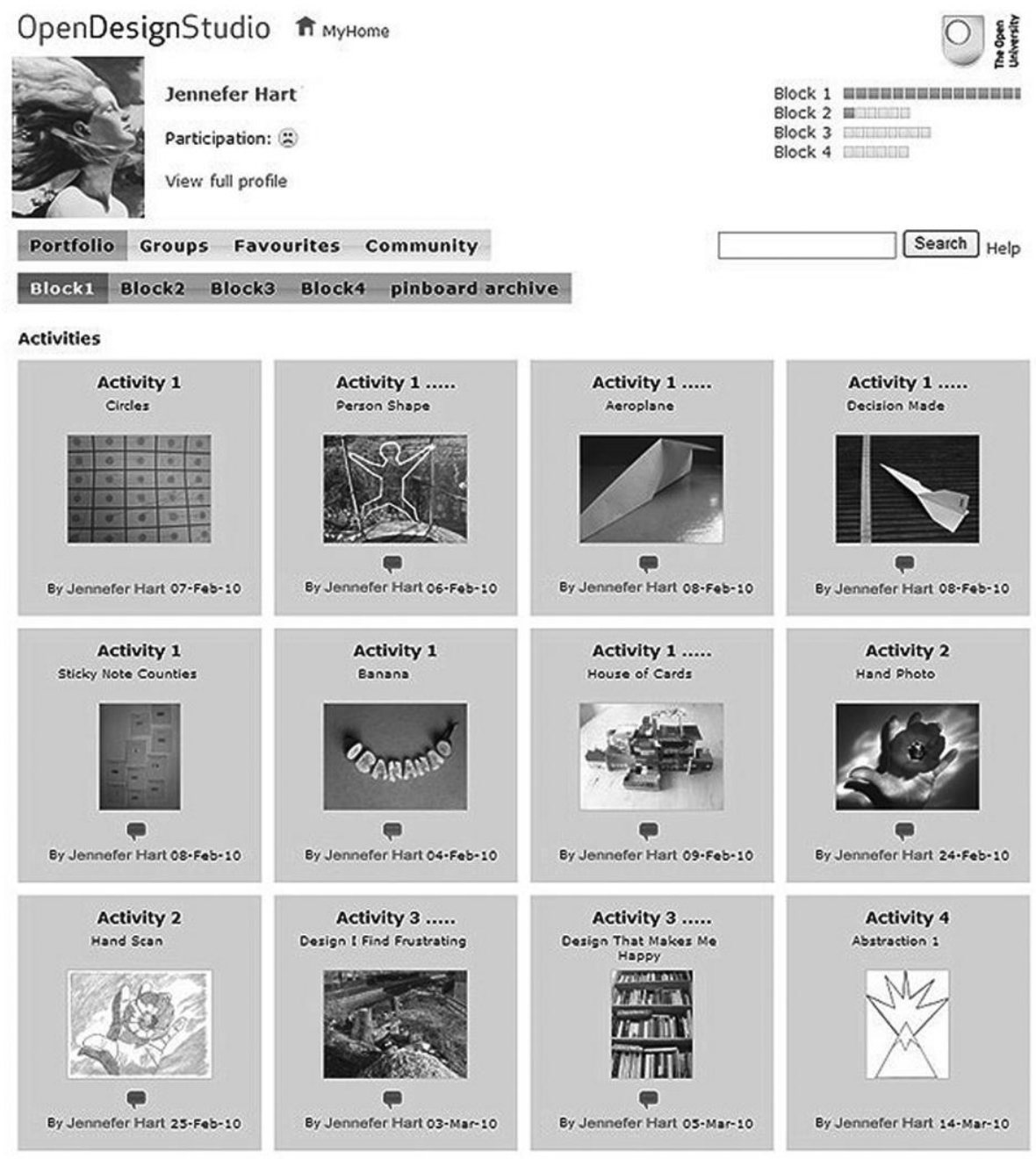

Figure 3 Screenshot of OpenDesignStudio portfolio page

When users join OpenDesignStudio they are encouraged to create a personal profile where they can add information about themselves and upload a profi le picture, similar to other social networking websites. The screenshot in Figure 3 shows a user's portfolio page with images that have been uploaded. Against each image a small red balloon indicates if they have received any comments from other members within the network. At the top right of the page there is a green indication bar that reveals the user's progress within the course. This technology is embedded within the learning objectives of the course and students are encouraged to actively engage with their community by sharing their design ideas and commenting on the postings of others. 


\section{Communication and learning across levels}

There are over 50 tutors (associate lecturers) involved in the tutoring of students across the three design courses, coordinated through 13 regional Open University offi ces around the UK. Although some associate lectures meet occasionally to run day schools they have limited opportunity to communicate across the programme and rely on the course tutor forums or private emails for communication. This study began with the intention to create opportunities for the sharing of knowledge and resources to take place within a virtual environment, through the use of Google Wave, a content sharing tool. Google Wave was chosen as it provides a private space for members to communicate and to share documents, as shown in Figure 4.

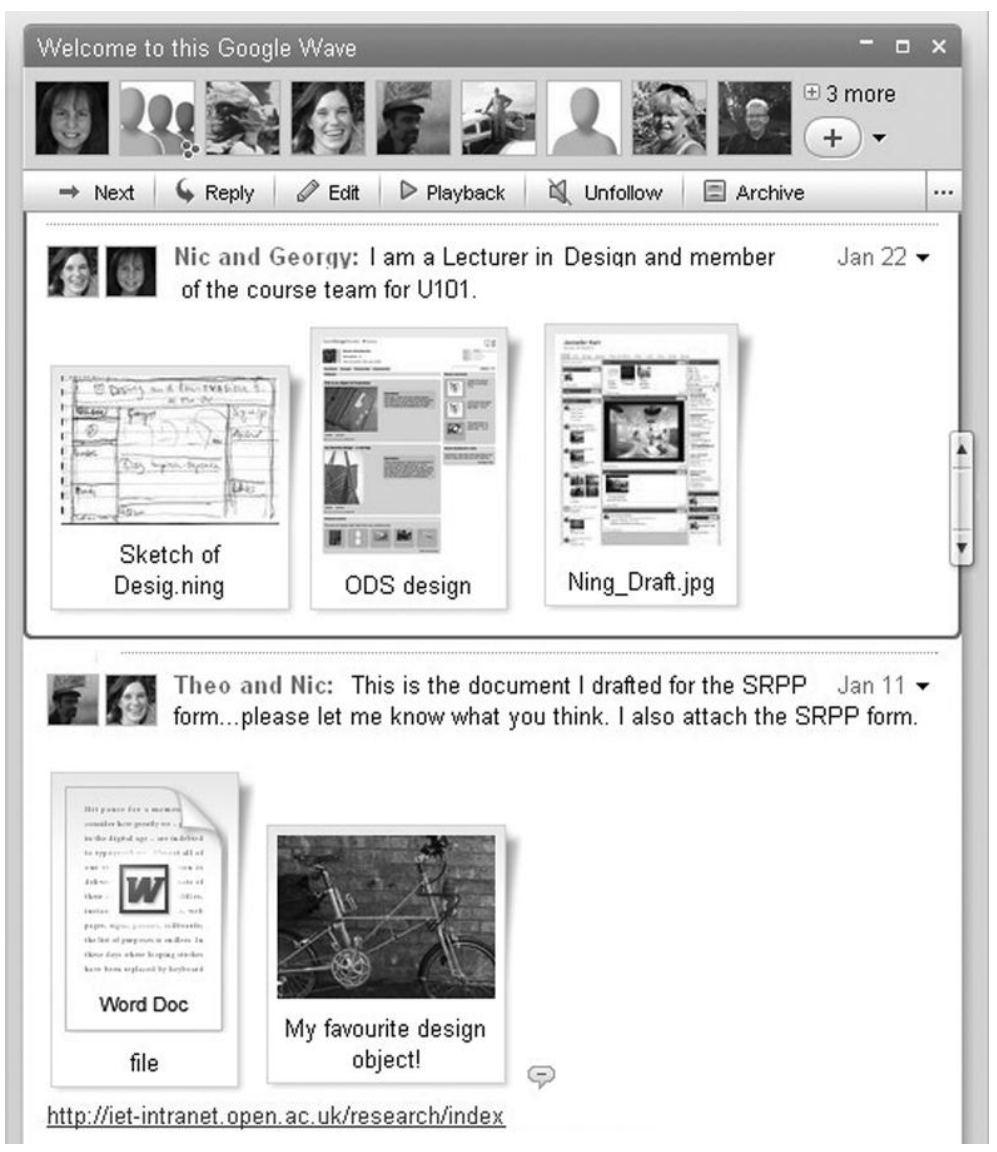

Figure 4 Screenshot of a Google Wave for tutors 


\section{Findings and observations}

The discussion is presented under six headings that represent some of the key attributes of a virtual design studio: social spaces, social roles, visual object sharing, personalisation, refl ective practice and cross-level communication.

\section{Social spaces}

In traditional face-to-face institutions, students and tutors have the benefi t of sharing the same physical space. There are social spaces such as 'the corridor' or the 'café' that provide the opportunity to chat or to share problems and experiences. Participants get the opportunity to peer over pinboards to view 'work-inprogress' of students at higher and lower levels. Also, there are spaces for 'exhibitions' and 'events' where organised activities bring people together allowing them to share experiences, formally showcase their work and communicate with the wider design community. The sharing of ideas through social interaction is viewed as essential to the development of a community of practice (Wenger, 1998).

Web 2.0 technologies provide opportunities to re-create these social spaces where informal learning can take place. Technologies that create virtual environments such as Second Life can augment the design studio space allowing actual design activities to occur within either a private or shared collaborative space. Social networks such as Ning can provide social spaces that facilitate communication across a network. Providing a networked learning environment can facilitate knowledge building and support collaborative designing (Seitamaa-Hakkarainen et al. 2004). This study provides a better understanding of how both informal and formal spaces can be created and developed within a future design atelier, but also illustrates how online social spaces can provide benefits across other subject disciplines. This is applicable not only to distance learning education, but can also be hugely beneficial for traditional face-to- face education which, as noted earlier, is moving towards a blended mode of teaching.

\section{Social roles}

The ATELIER-D team adopted a grounded theory approach in order to analyse the activity within the social networking sites (Facebook and Ning). Content analysis and social network analysis revealed the emergence of particular social structures and social roles. In this study social networking facilitated three kinds of learners: 'Content-focused Learners', who focus their discussion on concrete aspects, artefacts or methods of the design course; 'Content-orientated Socialisers', who focus their discourse on their personal experience within the course without explicit examples; and 'Brokers' who are actively engaged in transferring information between the two aforementioned kinds of learners (Schadewitz \& Zamenopoulos, 
Compass: The Journal of Learning and Teaching at the University of Greenwich, Issue 3, 2011

2009). The evidence suggests that future online design studios need to support social networking but appropriate conditions and motivations for sharing information within the network still need to be defi ned.

\section{Visual object sharing}

Effective learning in design requires a rich visual environment. Verbal communication is enhanced where visual cues are present and act to promote a collaborative discourse. This study revealed the positive role that visual object sharing plays in the formation of a community of learners. Many of the technologies employed within this study support a wide range of visual objects (photos, images, videos). The sharing of visual media in face-to-face design education is an essential element of teaching and learning. In keeping with the atelier model, a studio master can demonstrate 'knowing-in-action' through a variety of visual 33 objects backed up with verbal discourse. This is seen as essential to developing students' tacit knowledge as promoted by scholars such as Kvan (2001) and Schön (1983). The inclusion of visual object sharing is seen as a fundamental element of a design studio and further research into understanding the nature of an online visual object sharing would prove valuable in the development of a virtual design atelier.

\section{Personalisation}

In traditional face-to-face teaching, art and design students have access to dedicated studio space in which to work. However, this is increasingly under threat and hot-desking is becoming the norm. Where space is provided, students often personalise their space with current work, artefacts and images of inspiration. These spaces are often configured and reconfigured over time and become highly personalised workspaces expressing the students' identity. As noted by Binder et al. (2004), they also provide a place for students to showcase selected work to the wider design community. The ability of students to personalise their own design studio space encourages a sense of ownership and it facilitates the formation of what Wenger (1998) refers to as a 'community of practice'. Digital technologies that provide opportunities for personalisation and facilitate users to re-configure their learning space can therefore assist in providing a sense of ownership, which ultimately should lead to a sense of community. Technologies used within this study were chosen for their ability to provide personalisation of space (e.g. Ning). However, more research is needed to understand how users can be encouraged to take ownership of the technologies made available by education institutions.

\section{Reflective practice}

Design studio learning is dynamic with the convergence of knowledge and action. It exploits a particular cognitive capacity for evaluation - what Schön (1983) referred to as 'reflection-in-action'; the reflective dialogue that takes place within individuals and across a community through exchanges between 
participants (Broadfoot \& Bennett, 2003). Virtual environments (e.g. Second Life) can provide an immersive environment for creative and reflective thinking, while knowledge mapping tools (e.g. Compendium) can assist designers to reflect on their own creative process and communicate this process to others. The ability to record students' activity, artefact creation and related conversations can be enhanced with new technologies. For example, e-portfolios (e.g. OpenDesignStudio) keep track of students' design process and make development available for re-examination at any time. It seems that in documenting process, OpenDesignStudio might be superior to traditional techniques for facilitating reflective practice.

\section{Cross-level communication}

Within a traditional face-to-face design institution community awareness embraces both senior and junior students and their tutors. There is also a wider enculturation involving external stakeholders such as employers. Such cross-level and multi-participant communication enhances a learning environment and particularly those that seek to develop design skills and knowledge. It offers the opportunity to transfer tacit knowledge about, for example, the curriculum, assessment, the institution, employment opportunities or the wider profession. Traditionally the mechanisms for fostering such community building and enculturation have been many and various involving formal and informal means. Exhibitions, shared spaces, opportunities for interaction, committees etc all can play a vital role.

The mechanisms for achieving meaningful dialogue across levels of a virtual community are less clear. It seems likely that supporting the sharing of visual images, text and verbal discourses plays an important role. Bringing students and tutors from different levels is a worthy but diffi cult challenge - particularly the issues of motivation and reward for participation. Mechanisms for programme-wide communication can provide opportunities for users to socialise, communicate ideas, share resources and support each other.

\section{Key issues}

Despite the availability of some simple and easy to use Web 2.0 technologies today, combinations of tools are poorly researched and the creation of an online design studio still very much relies on a practical exploratory approach. The ATELIER-D study examined the use of a variety of digital technologies and the combination of selected tools to support design learning and teaching. Clearly such work makes demands on the digital literacy of both teachers and learners and, as with much design work, this is an area of skill and knowledge where teachers and learners journey together. A number of key issues emerged from ATELIER-D.

The issue of scalability and technology robustness was seen as a key challenge for the Open University as student populations frequently exceed 500 per module. This limits the application of certain technologies 
because of the level of support, training and expertise needed to successfully implement these technologies. Some Web 2.0 technologies would therefore be difficult to adopt with large student cohorts while others would require unrealistic levels of support. For example, the use of Second Life offers huge potential for design but would be problematic to implement such technology at a distance.

The technologies employed within this research were chosen for their potential to promote design thinking, aid communication and social collaboration. However, participants faced significant frustrations and difficulties, and reported feeling overwhelmed at the number of tools available to use. Both students and tutors reported on the challenges of having to overcome a steep learning curve when first encountering some of the tools, which resulted in low levels of engagement by some of the studies. The aspect of usability and appropriate use of any digital technology needs to be carefully considered and we therefore need to learn to adopt a digital wisdom when developing future learning technologies.

Embedding technologies within course learning objectives proved valuable. A seamless experience is particularly important when a number of different technologies are used. Providing tailor-made guides, that include clear instructions for using the technology and explanations how this will benefit the user, are essential. Additionally, it is important to allow adequate time for users to become familiar with new technologies and to become acquainted with their online peers. Virtual interactions can lack the social cues that take place in face-to-face interactions and users need time to get to know and trust their fellow peers and tutors in order for a virtual design atelier to grow.

\section{Summary}

Whilst design education has unique characteristics, the findings of this project have implications for other subjects that rely on the establishment of communities of learners and teachers. Subjects in the sciences, arts and humanities increasingly seek to engage learners in dynamic, creative activities that involve communication, reflection, collaboration and a sharing of skill and knowledge. The study described here reveals pointers to the fostering of rich dialogues, often visual, between participants that allow ideas and artefacts to receive the iteration and re-configurations they require. For the domain of design a virtual studio needs to be flexible, allowing participants to share and test their design ideas, map their thoughts and make connections with a variety of stakeholders.

The ATELIER-D project has begun to capture and model some of the key features that make up a traditional studio but the project has also given rise to new questions regarding the nature of a virtual visual object-sharing community. Through its links with curriculum development at the Open University, and particularly the creation of the new FHEQ level 4 course 'Design Thinking', ATELIER-D has demonstrated the potential for a new learningscape in design education. 
Compass: The Journal of Learning and Teaching at the University of Greenwich, Issue 3, 2011

The authors acknowledge the support of the Joint Information Systems Committee in funding the work reported here, and the contribution of other members of the project team: Georgy Holden, Nicole

Schadewitz, Peter Lloyd, Emma Dewberry and Giselle Ferreira.

\section{References}

Bennett, R. and Dziekan, V. (2005), 'Forming online communities of students, educators and professionals to explore collaborative modes of creative interaction and practice', ETD2005, $8^{\text {th }}$ International Electronic Theses and Dissertations Symposium Proceedings. Sydney: UNSW.

Binder, T., De Michelis, G., Gervautz, M., Jacucci, G., Matkovic, K., Psik, T. and Wagner, I. (2004), 'Supporting confi gurability in a mixed-media environment for design students', Personal and Ubiquitous Computing, Vol. 8. (5), pp. 310-25.

Broadfoot, O. and Bennett, R. (2003), 'Design Studios: Online?' Apple University Consortium Academic and Developers Conference Proceedings 2003, pp 9-21.

Kvan, T. (2000) 'The Pedagogy of Virtual Design Studios', Automation in Construction, vol. 10, no. 3, pp. 245-354.

Schadewitz, N. and Zamenopoulos, T. (2009), 'Towards an online design studio: a study of social networking in design distance learning', Proceedings of International Association of Societies of Design Research (IASDR) (CD-Rom) October 18-22, 2009, Seoul: Korea. Available at:

http://design.open.ac.uk/atelier-d/documents/IASDR_paper_web_pdf.pdf

Schön, D. (1983), The reflective practitioner: How professionals think in action. New York: Basic Books.

Sclater, N., Grierson, H., Ion, W. J. and MacGregor, S. P. (2001), 'Online collaborative design projects: overcoming barriers to communication', International Journal of Engineering Education, vol. 17, no.2, pp 189-196.

Seitamaa-Hakkarainen, P., Lahti, H. and Hakkarainen, K. (2004), Virtual Design Studio as a Learning Environment, A paper presented at the Scandinavian Summer Cruise at the Baltic Sea (theme: Motivation, Learning and Knowledge Building in the 21st Century), Organized by Karoliniska Institutet, EARLI SIG Higher Education, and IKIT, Stockholm, Sweden. Available online:

www.lime.ki.se/uploads/images/516/Seitamaa-hakkarainen_P_et_al.pdf 
Compass: The Journal of Learning and Teaching at the University of Greenwich, Issue 3, 2011

Shao, Y., Daley, L. and Vaughan, L. (2007), Exploring Web 2.0 for virtual design studio teaching.In ICT: Providing choices for learners and learning. Proceedings ascilite Singapore. Available online: www.ascilite.org.au/conferences/singapore07/procs/shao.pdf

Wenger, E. (1998), 'Communities of Practice; Learning as a Social System', In: Systems Thinker, June 1998. 